\title{
Intermittent feeding programme and addition of Bacillus subtilis based probiotics to the diet of growing broiler chickens: Influence on growth, hepatic enzymes and serum lipid metabolites profile
}

\author{
Hamid Reza Aliakbarpour', Mohammad Chamani', Godrat Rahimi², Ali Asghar Sadeghi' \\ and Durdi Qujeq ${ }^{3}$ \\ 'Department of Animal Science, Science and Research Branch, Islamic Azad University, Tehran, Iran, ${ }^{2}$ Laboratory for \\ Molecular Genetics and Animal Biotechnology, Department of Animal Science, Sari Agricultural Sciences and Natural \\ Resources University, Sari, Iran, ${ }^{3}$ Department of Biochemistry and Biophysics, Faculty of Medicine, Babol University of \\ Medical Sciences, Babol, Iran
}

\begin{abstract}
This study was conducted to examine the effects of Intermittent feeding programme (IFP) and Bacillus subtilis-based probiotic (BSP) addition in diet on liver malic enzyme and isocitrate dehydrogenase activity, lipid metabolism and performance in broiler chickens. Five hundred and four one-day old male broiler chicks were randomly allocated in four experimental treatments (T1, T2, T3 and T4). Groups $\mathrm{T} 1$ (control diet) and $\mathrm{T} 3$ (Bacillus subtilis-based probiotic diet) were fed ad libitum, whereas groups T2 (control diet) and T4 (Bacillus subtilis-based probiotic diet) served as IFP from day 8 to the end of the experiment. The data on initial body weight, weekly feed consumption and body weight gain were recorded up to six weeks of age. Carcass composition, blood parameters and hepatic enzyme activity were measured at the end of the experiment. Although body weight gain was not significantly different among any of the treatments, the birds raised under IFP consumed significantly $(P<0.05)$ lower feed $(207 \mathrm{~g})$ and utilized their feed more efficiently (1.78) than those of the control group fed ad libitum (1.84). Carcass weight as a percentage of live weight was not affected by probiotic supplementation on the diet, but IFP significantly reduced $(P<0.05)$ broiler carcass weight. However, the liver malic and isocitrate dehydrogenase enzyme activity was not significantly different between IFP and BSP groups. All serum lipid metabolites concentration decreased $(P<0.05)$ with probiotic treatment. It may be concluded that dietary supplementation with
\end{abstract}

Archiv Tierzucht 56 (2013) 40, 410-422

doi: $10.7482 / 0003-9438-56-040$

Corresponding author:

Mohammad Chamani; email: fariborzchamani@yahoo.com

Department of Animal Science, Science and Research Branch, Islamic Azad University, Tehran, Iran

(c) 2013 by the authors; licensee Leibniz Institute for Farm Animal Biology (FBN), Dummerstorf, Germany. This is an Open Access article distributed under the terms and conditions of the Creative Commons Attribution 3.0 License (http://creativecommons.org/licenses/by/3.0/).
Received: 9 October 2012

Accepted: 15 January 2013 Online: 22 March 2013 
BSP may influence the pathway of fat metabolism through promotion and/or suppression of serum lipid metabolites.

Keywords: Intermittent feeding program, Bacillus subtilis, isocitrate dehydrogenase enzyme, malic enzyme, broiler

\begin{abstract}
Abbreviations: AFP: abdominal fat pad, BSP: Bacillus subtilis-based probiotic, HDL: high density lipoprotein, ICD: isocitrate dehydrogenase, IFP: intermittent feeding programme, LDL: low density lipoprotein, MAE: malic enzyme, NADPH: nicotinamide adenine dinucleotide phosphate, NEFA: non-esterified fatty acid, TG: triglyceride, VLDL: very low density lipoprotein
\end{abstract}

\title{
Introduction
}

Utilization of successful genetic selection techniques in order to rapid growth and efficient feed conversion rate in commercial broiler chickens has resulted in different metabolic disorders such as hyperphagia, obesity (Yang et al. 2010) and leg problems (Wijtten et al. 2010). Ad libitum feeding ensures a high feed intake and over-feeding can induce de novo synthesis of fatty acids in liver and lipogenesis (Hermier et al. 1997). The increase of fat deposition in carcass effectively decreases the carcass quality. However, the high growth under ad libitum feeding is occasionally associated with increasing mortality and severe leg problems. Feed restriction in poultry has been commonly used to control the body weight (Fassbinder-Orth \& Karasov 2006) and alleviate metabolic disorders such as ascites (Özkan et al. 2006) and leg problems (Wijtten et al. 2010, Saffar \& Khajali 2010). Also the effect of feed restriction on lipid metabolism was documented in studies of some research groups (Lippens et al. 2009, Yang et al. 2010). Feed restriction is classified into two forms including a quantitative feed restriction where the birds' access to the feed physically declines during certain times of the day and a qualitative feed restriction, where birds' full access to particular nutrients decreased through the provision of a feed diluted with inert fibres (Fanooci \& Turki 2010). According to the previous investigations, the response of the bird to a feed restriction programme is related to feeding strategies (Urdaneta-Rincon \& Leeson 2002), severity of restriction (Lippens et al. 2009) and genetic make-up (Saleh et al. 2005). Therefore, usage of an appropriate method of feed restriction for broilers is difficult (Lippens et al. 2009).

Probiotics have been defined as live microbial feed additive that in adequate amounts of usage can beneficially influence intestinal microflora balance and improve animal performance (Xiangqian et al. 2008, Mountzouris et al. 2010). Today, addition of probiotic in diet is a common strategy for animal nutrition, because probiotic is a natural growth promoter instead of feed antibiotic (Rekiel et al. 2007). Adding probiotic in the diet improves the animal immune system and the host's resistance to enteric pathogens, affects intestinal morphology as well as intestinal function, feed conversion, weight gain and performance of birds (Dalloul et al. 2003, Chichlowski et al. 2007, Vila et al. 2009, Ohh 2011). Li et al. (2006) also reported that addition of Bacillus subtilis culture to the layer diet decreased cholesterol concentration in egg yolk.

Nicotinamide adenine dinucleotide phosphate (NADPH) is an essential component for de novo synthesis of fatty acids in the liver (Xu et al. 2003). Nicotinamide adenine dinucleotide 
phosphate is produced by the activity of malic enzyme (MAE) and isocitrate dehydrogenase (ICD) in the liver (De Beer et al. 2007, Xu et al. 2003). Thus, better insight into these liver enzymes is extremely important to understand the main biological role of these enzymes in lipid metabolism of broiler birds.

While lipogenesis and export of lipid in the liver is related to the nutrient status of the diet (Yang et al. 2010), the effect of intermittent feeding programme (IFP) and/or addition of Bacillus subtilis-based probiotics (BSP) on liver enzymes activity is poorly understood. The main objective of the current study was to investigate the effect of IFP in the presence or absence of BSPs in diet on liver MAE and ICD enzymes activity, lipid metabolism and broiler performance.

\section{Materials and Methods}

\section{Birds, feeding and housing}

This experiment was conducted on five hundred and four one-day old male broilers consisting of four treatments and six replicates. All male broilers were obtained from the hatchery of Arian breeding centre (Babol, Iran) and were randomly assigned into one of the four treatments on the basis of equal body weight (21 birds kept on each replicate). Four treatments included T1): the control group was a corn-soybean based commercial diet fed ad libitum; T2): a group was fed similar to the control diet but subjected to IFP; T3): a group was fed a control diet containing BSP and T4): a group was fed the same diet as group 3 and subjected to IFP. All dietary treatments were formulated to meet the Arian broilers' requirements as well as NRC (1994) recommendation for starter (1 to $14 \mathrm{~d}$ ), grower (15 to $28 \mathrm{~d}$ ) and finisher (29 to $42 \mathrm{~d}$ ) of growth periods (Table 1). Intermittent feeding programme in treatment 2 and 4 was applied from day 8 to the end of the experiment with 5 feeding times per day. Feeding was done from 1 to 2,6 to 7, 11 to 12,16 to 17 and 21 to 22 each day. The level of $50 \mathrm{mg}$ of BSP, that was commercially available as Calsporin (Calpis Co., Ltd. Tokyo, Japan), was supplemented per $\mathrm{kg}$ of the basal diet for broilers in group 3 and 4 . Before addition of probiotic to the experimental diets, culturing techniques were used for enumeration of Bacillus subtilis in trypticase soy agar (Merck, Darmstadt, Germany) after dilution in sterile saline (Leuschner et al. 2003). Results were expressed as $\log _{10}$ colony forming units per gramme of probiotic product. Broilers were reared on wood shavings litters and assigned to a clean floor pen $\left(2 \mathrm{~m}^{2}\right)$ with one hanging tube feeder and four nipple drinkers. The lighting schedule, the temperature and healthy programme throughout the experiment were provided according to the Arian broiler breeder management guidelines. For inhibition of cross contamination of probiotic between experimental pens, the treatment units were separated by plastic sheets (Aliakbarpour et al. 2012). Chickens were weighed weekly to estimate their growth. To determine daily feed intake by each pen the uneaten feed was discarded and fresh feed was replaced in feeders at the end of each day. Feed conversion ratio was calculated weekly. 
Table 1

Feed composition and ingredients of experiment basal diets

\begin{tabular}{lccc}
\hline Component & Starter $(1$ to $14 \mathrm{~d})$ & Grower $(15$ to $28 \mathrm{~d})$ & Finisher $(29$ to $42 \mathrm{~d})$ \\
\hline Ingredient, $\%$ & & & \\
Corn & 57.1 & 62.4 & 67.6 \\
Soybean meal & 37.0 & 32.0 & 27.0 \\
Vegetable fat & 1.25 & 1.70 & 1.58 \\
DL-Met & 0.29 & 0.23 & 0.22 \\
L-Lys HCl & 0.07 & 0.03 & 0.09 \\
Theronin & 0.05 & 0.03 & 0.04 \\
Dicalcum phosphate & 1.85 & 1.61 & 1.51 \\
Limestone & 1.15 & 0.98 & 0.95 \\
NaCl & 0.32 & 0.28 & 0.28 \\
Soduim Bicarbonate & 0.15 & 0.1 & 0.1 \\
CholinCholoride & 0.17 & 0.14 & 0.14 \\
Vitamin permix1 & 0.3 & 0.25 & 0.25 \\
Mineral permix2 & 0.3 & 0.25 & 0.25 \\
Calculated analysis & & & \\
ME, kcal/ kg & 2907 & 3003 & 3050 \\
Crude protein, \% & 22.13 & 20.09 & 18.21 \\
Ca, \% & 1.04 & 0.90 & 0.85 \\
Avp, \% & 0.71 & 0.65 & 0.61 \\
Met, \% & 0.58 & 0.50 & 0.47 \\
Lys, \% & 1.15 & 1.00 & 0.92 \\
Thr, \% & 0.76 & 0.67 & 0.62 \\
\hline
\end{tabular}

'The vitamin mix provided the following (per $\mathrm{kg}$ of diet): thiamine mononitrate, $2.5 \mathrm{mg}$; nicotinic acid, $45 \mathrm{mg}$; riboflavin, $6 \mathrm{mg}$; d-calcium pantothenate, $15 \mathrm{mg}$; vitamin B12 (cobalamin), $0.025 \mathrm{mg}$; pyridoxine hydrochloride, $3 \mathrm{mg}$; d-biotin, $0.15 \mathrm{mg}$; folic acid, $1.5 \mathrm{mg}$; choline chloride, $840 \mathrm{mg}$; cholecalciferol, $4000 \mathrm{IU}$; trans-retinyl acetate, $10000 \mathrm{IU}$; all-rac-a-tocopheryl acetate, $55 \mathrm{IU}$; ethoxyquin, $1.25 \mathrm{mg}$. ${ }^{2}$ The trace mineral mix provided the following (per $\mathrm{kg}$ of diet): manganese (manganese oxide), $120 \mathrm{mg}$; iron (ferrous sulphate), $40 \mathrm{mg}$; zinc (zinc oxide), $100 \mathrm{mg}$; copper (copper sulphate), $16 \mathrm{mg}$; iodine (calcium iodate), $1.25 \mathrm{mg}$; selenium (sodium selenate), $0.3 \mathrm{mg}$.

\section{Carcass composition}

At the end of the experiment, six chickens per replicate were randomly selected and slaughtered for carcass analysis. The heads, feathers, feet and viscera were removed after slaughter. Then, abdominal fat pad was removed and weighed. Carcass weight was calculated as the percentage of body weight (Petek et al. 2005) and the relative percentage of abdominal fat pad, wing, thigh, breast and back for individual broilers were estimated as percentage of carcass weight.

\section{Liver enzyme assays}

After slaughter, livers were stored at $-70^{\circ} \mathrm{C}$ prior to analysis. The liver supernatants were prepared according to the methodology of Ochoa (1955) and Plant (1962). Subsequently, the activities of MAE and ICD enzymes were evaluated according to Geer et al. (1980) and the procedures recommended by the manufacturer of the kits (BioVision, USA, Cat no.K756-100), respectively. 


\section{Blood biochemical parameters assays}

One bird from each pen was randomly chosen at the end of the experiment and blood samples were taken via the wing vein and centrifuged at $2000 \times \mathrm{g}$ for $30 \mathrm{~min}$. Then, serum was separated and stored at $-20^{\circ} \mathrm{C}$. Serum level of triglyceride (TG), high density lipoprotein $(\mathrm{HDL})$ and low density lipoprotein (LDL) were estimated according to the procedures recommended by the manufacturer of the specific kits (Pars Azmun Company, Tehran, Iran). Total non-esterified fatty acid (NEFA) was determined using NEFA kit (Randox Laboratories Ltd, United Kingdom, Lot number 350FA). Analyses for serum parameters were conducted with an automated clinical chemistry analyser (Hitachi 911, Tokyo, Japan). Very low density lipoprotein (VLDL) was calculated according to Rifai et al. (1992).

\section{Statistical analyses}

The effects of BSP and IFP on liver enzymes, blood parameters and growth performance were determined in a $2 \times 2$ factorial arrangement. Before all data were analysed using the GLM procedures of SAS (SAS Institute Inc. 2003), differences between means were examined using Duncan's multiple range test and the statements of statistical significance were based on $P<0.05$.

\section{Results}

\section{Growth performance}

Data on body weight gain, feed intake and feed conversion ratio of experimental groups throughout the experiment are summarized in Table 2 . The feed intake significantly decreased $(P<0.05)$ due to IFP at 8 to 42 days of age. However, it was not affected by IFP between 35 to 42 days of age. This feeding procedure significantly reduced body weight at 8 to 21 days of age $(P<0.05)$ but there was no main effect of feeding strategies on body weight gain at 22 days of age to the end of the experiment. Similarly, IFP significantly improved feed conversion ratio between 8 to 42 day of age $(P<0.05)$.

Addition of probiotic did not significantly affect body weight gain or feed intake during rearing period $(P>0.05)$, but between 36 to 42 days of age feed conversion ratio was significantly improved by probiotic addition $(P<0.05)$. No interaction was found between BSP and IFP on growth performance in this experiment.

\section{Determination of carcass cut yield}

In this study, weight of wing, abdominal fat pad, thigh, breast and back which was presented as percentage of the live body weight, did not differ significantly $(P>0.05)$ among the treatments (Table 3). There was a significant decrease in carcass weight, wing and back based on body weight percentage due to feeding strategies $(P<0.05)$. The carcass composition parameters were not significantly affected by BSP $(P>0.05)$. At the present experiment, no interaction was found between BSP and IFP on carcass composition. 


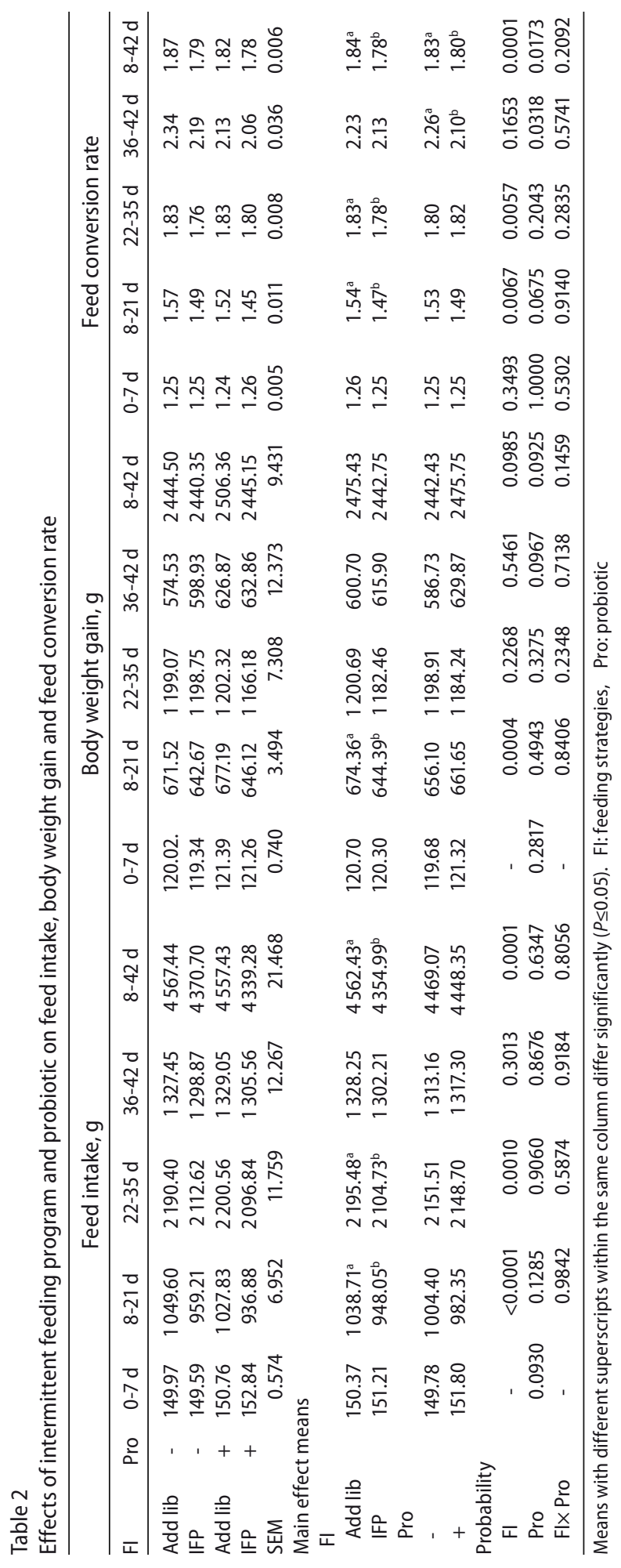




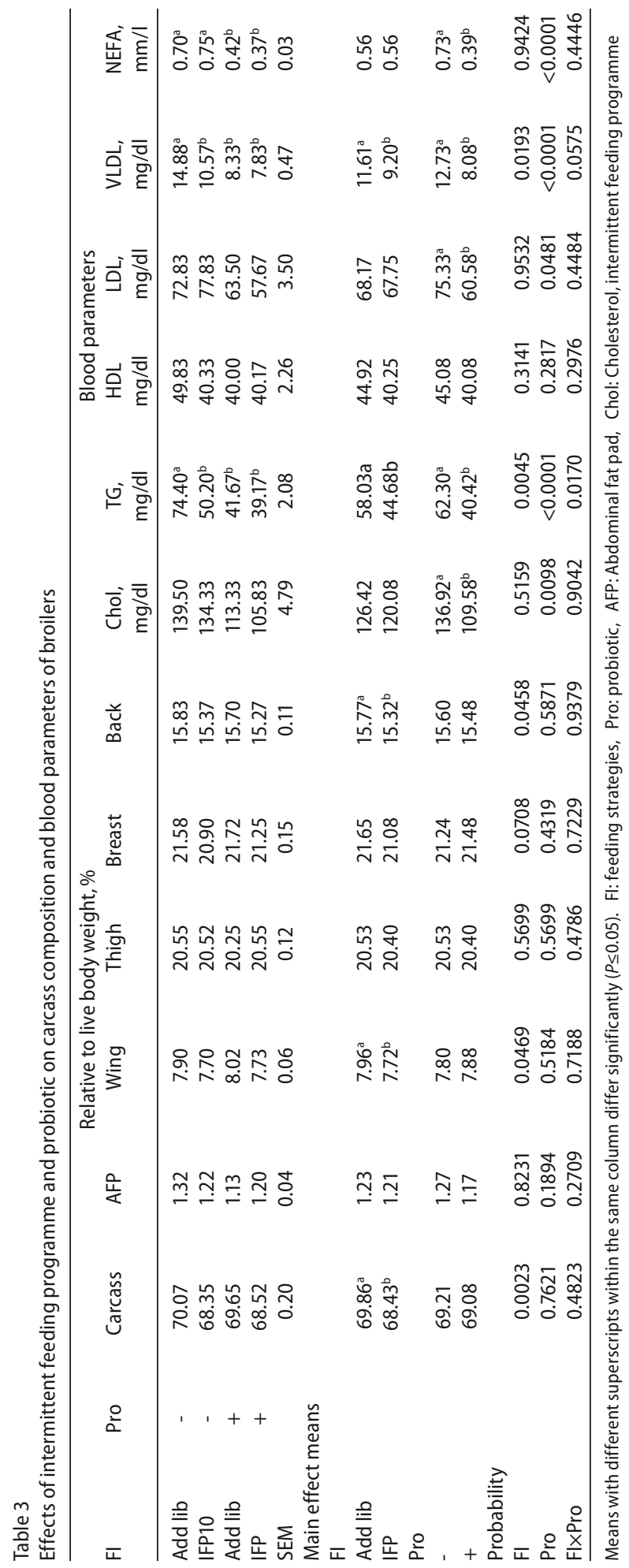




\section{Liver enzymes and blood parameters assay}

In this study, ICD and MAE activity did not differ significantly among the treatments $(P>0.05$, data not shown). Feeding strategy did not have an effect on serum metabolites related to fat metabolism such as cholesterol, NEFA and lipoproteins HDL and LDL (Table 3), but there was a significant decrease in TG and VLDL by feeding strategy $(P<0.05)$. In this experiment, there was a significantly decrease in TG, cholesterol, NEFA and lipoproteins LDL and VLDL due to BSP $(P<0.05)$, but there was no main effect of probiotic on serum HDL $(P>0.05)$. No interaction was found between BSP and IFP on liver enzymes and blood parameters except for plasma TG concentration.

\section{Discussion}

There are contradictory reports on the effect of feed restriction on broiler performance. Some researchers had reported no significant difference in body weight of broilers when they received intermittent feeding and broilers fed ad libitum (Saffar \& Khajali 2010, Svihus et al. 2010). However, Petek et al. (2005) demonstrated that IFP effectively decreased body weight. In this experiment, IFP decreased body weight gain at the early phase of age ( 8 to 21 days) $(P<0.05)$ but between the 22 to 42 days of age body weight gain was not affected by IFP $(P>0.05)$. Various factors such as timing, severity and duration of the restriction, gender and age of the parent stock, feed texture (Lippens et al. 2009), genetic make-up (Saleh et al. 2005) and feeding strategies (Urdaneta-Rincon \& Leeson 2002) can influence growth performance of feed-restricted birds. It has been reported that under feed restriction, the digestive system probably indicates an adaptive response (Özkan 2010) and birds are able to use the crop and proventriculus-gizzard for feed storage in long periods of feed deprivation (Buyse et al. 1993). The crop is used as an intermediate storage organ in broiler chickens (Svihus et al. 2010). Therefore, these birds can maintain their growth rate during meal feeding. Changes in the enzymatic or absorptive capacity of the gastrointestinal tract or changes in post-absorptive processes can change feed efficiency (Fassbinder-Orth \& Karasov 2006). The improvement in feed efficiency observed in feed-restricted chickens was probably attributed to reduced overall maintenance requirements, improvement of chemical digestion and nutrient absorption in the broiler gut (Pinheiro et al. 2004). The results of our experiment showed that intermittent-fed birds were able to adapt to the feeding strategy for improving feed conversion and nutrient requirements, because they had similar body weight gain with control birds from 22 days of age to the end of the study.

In previous studies, researchers indicated that addition of probiotic can stimulate growth and improve feed conversion ratio in broilers (Onderci et al. 2008, Bansal et al. 2011). In this study, a BSP diet did not affect body weight gain and feed intake but improved birds feed conversion ratio $(P<0.05)$ from 36 days of age to the end of the experiment. It was documented that probiotic can improve intestinal microbiota, the integrity of the intestinal mucosal barrier, digestive and immune function of intestine and broiler health (Tellez et al. 2006, Mountzouris et al. 2010). There are conflicting reports on the effects of probiotic application in poultry industry. Different factors such as bird age, overall farm hygiene, environmental stress, hydrophobicity of the probiotic bacterial cell surface, composition of microbial species, concentration of bacteria in probiotic and dosage, methods of using, frequency 
of application, the combination of probiotics and synergistically acting components are effective on probiotic efficacy (Karimi et al. 2008, Awad et al. 2009, Flint \& Garner 2009, Mountzouris et al. 2010).

Lipids and especially triglycerides may be stored in adipocytes, hepatocytes and growing oocytes in the birds (Hermier 1997). Deposition of fat in the abdominal area of the body is not suitable for customers. Reduction of deposition of lipids and increase of lipolysis is a main goal to improve the feed conversion and product cost. Environmental stress, energy status and hormonal stimuli can affect lipogenesis in birds (Lee et al. 2009). In the present study, there was no significant difference in AFP content as percentage of body weight among the treatments (Table 3). Similarly, Urdaneta-Rincon \& Leeson (2002), Saleh et al. (2005), Lippens et al. (2009) and Saffar \& Khajali (2010) reported that feed restriction had no effect on abdominal fat deposition. Although, some previous investigation has shown that feed restriction resulted in obesity and an increase in abdominal fat in broilers (Zhan et al. 2007, Wijtten et al. 2010). On the other hand, some reports showed that feed restriction decreased fat pad or abdominal fat in broilers (Santoso 2001, Moritz et al. 2005).

In our experiment, a significant decrease in carcass, wing and back weight (as percentage of the live body weight) was observed due to the IFP $(P<0.05)$. This result is not in agreement with the report of Petek et al. (2005), who concluded that intermittent feeding had no significant influence on carcass weight based on percentage of body weight. Researchers indicated that bird response to feed restriction could be influenced by various factors such as different feeding strategies applied (Urdaneta-Rincon \& Leeson 2002), restriction programmes, duration of feed restriction (Khetani et al. 2009) and the excess of energy consumed (Tahmoorespur et al. 2010).

Usage of probiotic in animal diet improved meat quality (Ko et al. 2008, Zhou et al. 2010). In the present experiment, we studied the effect of probiotic on broiler carcass composition to evaluate the quality of bird yields. The findings of our study showed that the usage of the BSP at a dose of $50 \mathrm{mg}$ per $\mathrm{kg}$ diet did not affect Arian male broilers abdominal fat pad and other carcass cut yields. Our findings are in agreement with the results of Pelicano et al. (2003), who indicated that probiotics inclusion of bacillus, Lactobacillus or Saccharomyces cerevisiae, had no effect on abdominal fat and carcass yields.

Nicotinamide adenine dinucleotide phosphate is an essential component for de novo synthesis of fatty acids in the liver, which is produced by the activity of ICD, MAE and glucose6-phosphate dehydrogenase in the cytosol (Xu et al. 2003). Malic enzyme (EC 1.1.1.40) catalyses the oxidative de-carboxylation of malate to pyruvate and $\mathrm{CO}_{2}$ while converting $\mathrm{NADP}^{+}$to NADPH (Goodridge et al. 1989). Glucose is a mediator for transcription of fatty acid synthesis and MAE (Hillgartner \& Charron 1998). The MAE can produce most of the need for NADPH for the process of de novo synthesis of fatty acids and production of palmitate in birds (Goodridge et al. 1989, Hillgartner \& Charron 1998). Palmitate is the precursor molecule for the production of other fatty acids (Adams \& Davis 2001). Isocitrate dehydrogenase (EC 1.1.1.42) catalyses the oxidative decarboxylation of isocitrate to a-keto-glutarate and $\mathrm{CO}_{2^{\prime}}$ simultaneously generating NADPH from $\mathrm{NADP}^{+}$(De Beer et al. 2007). Xu et al. (2003) reported that a decline in total activities of the enzymes glucose-6-phosphate dehydrogenase, MAE, ICD and lipoprotein lipase in the fat reduces the deposition of subcutaneous fat. There are reports that indicate feed restriction can influence enzymatic activity in lipid metabolism. 
Santoso (2001) reported that hepatic acetyle-CoA carboxylase activity was reduced in early feed-restricted broiler and resulted in reduction of final body fat deposition. According to previous investigations, nutritional conditions such as starvation (Goodridge et al. 1989), feeding a low-carbohydrate, high-fat diet and feeding high-carbohydrate for a long duration, low-fat diet (Hillgartner \& Charron 1998) and dietary protein (Adams \& Davis 2001) can affect the activity of fatty acid synthesis and MAE in birds. Under the condition of our experiment, IFP and BSP did not affect the liver MAE and ICD activity.

Lipoproteins are assembled and secreted to the bloodstream by the liver and intestine. Liver synthesis HDL and VLDL and it is the major site for synthesis of cholesterol and phospholipids. Triglyceride is the major product of liver de novo synthesis (Hermier et al. 1997). Very low density lipoproteins and HDL are main carriers of TG and cholesterol, respectively. The nature of lipid deposition in the body is related to the availability of TG and their transportation by VLDL. Lipoprotein lipase catalyses the breakdown of TG from portomicrons and VLDL to free fatty acid and glycerol (Chen et al. 2005). Then the increase of free fatty acids in blood can induce deposition of lipid in muscle and adipose tissue (Xu et al. 2003). Although Yang et al. (2010) reported that feed restriction can affect lipid metabolism by catalysing tissue lipids to provide body energy, which increased serum total cholesterol level, there are different reports on the effect of feed restriction on blood lipid metabolites. Zhan et al. (2007) reported serum free fatty acid and VLDL to be slightly increased, whereas serum TG decreased $(P<0.01)$ in feed-restricted compared to ad libitum birds. Concentrations of total cholesterol and HDL cholesterol in serum were significantly higher in early feed restriction group at $14 \mathrm{~d}$ compared to ad libitum bird $(P<0.05)$ as documented by Yang et al. $(2010)$. According to the study of Santoso (2001), the concentration of serum TG was significantly reduced in the early feed restriction group $(P<0.01)$, whereas cholesterol concentration was not affected $(P>0.05)$. In our experiment, although TG and VLDL were decreased by IFP, serum level of HDL, cholesterol, total NEFA and LDL were not significantly affected by IFP $(P>0.05)$.

Cenesiz et al. (2008) found that addition of kafir (includes Lactobacillus, Streptococcus and yeast species) to drinking water could reduce serum cholesterol and lipid levels in broilers. Fazeli et al. (2010) showed that addition of Lactobacillus plantarum to mice diet reduced serum cholesterol, LDL and TG. Cavallini et al. (2009) reported that addition of Enterococcus faecium-based probiotic to a rabbit diet decreased the blood TG. Dibaji et al. (2012) found that the use of symbiotic at a certain concentration in diet could significantly reduce the LDL and HDL to LDL ratio in serum but did not affect HDL, VLDL, TG and cholesterol levels. At this experiment, BSP addition decreased serum lipid metabolites except for HDL and there was no IFP effect in birds receiving BSP in the diet. According to previous investigations, some mechanisms are hypothesized for the effect of probiotic microorganism on lipid metabolism. They can be listed as: posing bile salt hydrolase activity and precipitation of cholesterol by some microorganisms such as Lactobacillus, Bifidobacterium (Sudha et al. 2009), incorporation of cholesterol into or binding to bacterial microorganism (Liong \& Shah 2005) and making of short-chain fatty acids by probiotic bacteria (Ooi \& Liong 2010).

In conclusion, the results of this study indicated that IFP or BSP did not affect hepatic malic and isocitrate dehydrogenase enzymes activity and abdominal fat content measured as percentage of live body weight. However, IFP significantly decreased feed intake and improved feed conversion ratio which is economically important in broiler breeding industry. 


\section{Acknowledgments}

We thank Dr. H. Shojaei and Mr. K. Yousefi from Arian broiler line breeding centre for generously providing broiler chicks, rearing and sample collection. We wish to express our gratitude to Mr. R. Dozori from veterinary department, Islamic Azad University of Babol for his kind assistance during liver sampling. We also thank Dr. M. Sharbatdaran and Mr. R. Ramzanpour from medical laboratory department, Babol University of Medical Sciences for their technical assistance.

\section{References}

Adams KA, Davis AJ (2001) Dietary Protein Concentration Regulates the mRNA Expression of Chicken Hepatic Malic Enzyme. J Nutr 131, 2269-2274

Aliakbarpour HR, Chamani M, Rahimi G, Sadeghi AA, Qujeq D (2012) The Bacillus subtilis and Lactic Acid Bacteria Probiotics Influences Intestinal Mucin Gene Expression, Histomorphology and Growth Performance in Broilers. Asian-Aust J Anim Sci 25, 1285-1293

Awad WA, Ghareeb K, Abdel-Raheem S, Böhm J (2009) Effects of dietary inclusion of probiotic and synbiotic on growth performance, organ weights, and intestinal histomorphology of broiler chickens. Poult Sci 88, 49-56

Bansal GR, Singh VP, Sachan N (2011) Effect of Probiotic Supplementation on the Performance of Broilers. Asian J Anim Sci 5, 277-284

Buyse J, Adelsohn DS, Decuypere E, Scanes CG (1993) Diurnal-nocturnal changes in food intake, gut storage of ingesta, food transit time and metabolism in growing broiler chickens: A model for temporal control of energy balance. Br Poult Sci 34, 699-709

Cavallini DCU, Bedani R, Bomdespacho LQ, Vendramini RC, Rossi EA (2009) Effects of probiotic bacteria, isoflavones and simvastatin on lipid profile and atherosclerosis in cholesterol-fed rabbits: a randomized double-blind study. Lipids Health Dis 8: 1

Cenesiz S, Yaman H, Ozcan A, Kart A, Karademir G (2008) Effects of kefir as a probiotic on serum cholesterol, total lipid, aspartate amino transferase and alanine amino transferase activities in broiler chicks. Med Weter 64, 168-170

Chen KL, Chi WT, Chiou PW (2005) Caponization and testosterone implantation effects on blood lipid and lipoprotein profile in male chickens. Poult Sci 84, 547-552

Chichlowski M, Croom WJ, Edens FW, McBride BW, Qiu R, Chiang CC, Daniel LR, Havenstein GB, Koci MD (2007) Microarchitecture and Spatial Relationship Between Bacteria and Ileal, Cecal, and Colonic Epithelium in Chicks Fed a Direct-Fed Microbial, PrimaLac, and Salinomycin. Poult Sci 86, 1121-1132

Dalloul RA, Lillehoj HS, Shellem TA, Doerr JA (2003) Enhanced mucosal immunity against Eimeria acervulina in broilers fed a Lactobacillus-based probiotic. Poult Sci 82, 62-66

De Beer M, Rosebrough RW, Russell BA, Poch SM, Richards MP, Coon CN (2007) An Examination of the Role of Feeding Regimens in Regulating Metabolism During the Broiler Breeder Grower Period. 1. Hepatic Lipid Metabolism. Poult Sci 86, 1726-1738

Dibaji SM, Seidavi A, Asadpour L (2012) Effect of dietary inclusion of the synbiotic Biomin IMBO on broilers' some blood metabolites. Res Opin Anim Vet Sci 2, 10-13

Fanooci M, Torki M (2010) Effects of Qualitative Dietary Restriction on Performance, Carcass Characteristics, White Blood Cell Count and Humoral Immune Response of Broiler Chicks. Global Veterinaria 4, 277-282

Fassbinder-Orth CA, Karasov WH (2006) Effects of Feed Restriction and Realimentation on Digestive and Immune Function in the Leghorn Chick. Poult Sci 85, 1449-1456

Fazeli H, Moshtaghian J, Mirlohi M, Shirzadi M (2010) Reduction in serum lipid parameters by incorporation of a native strain of Lactobacillus Plantarum A7 in Mice. Iranian Journal of Diabetes and Lipid Disorders 9, 1-7

Flint JF, Garner MR (2009) Feeding beneficial bacteria: A natural solution for increasing efficiency and decreasing pathogens in animal agriculture. J Appl Poult Res 18, 367-378 
Geer BW, Krochko D, Oliver MJ, Walker VK, Williamson JH (1980) A comparative study of the NADP-malic enzymes from Drosophila and chick liver. Comp Biochem Physiol B 65, 25-34

Goodridge AG, Crish JF, Hillgartner FB, Wilson SB (1989) Nutritional and hormonal regulation of the gene for avian malic enzyme. J Nutr 119, 299-308

Hermier D (1997) Lipoprotein Metabolism and Fattening in Poultry. J Nutr 127, 8055-8085

Hillgartner FB, Charron T(1998) Glucose stimulates transcription of fatty acid synthase and malic enzyme in avian hepatocytes. Am J Physiol Endocrinol Metab 274, e493-501

Karimi Torshizi MA, Rahimi S, Mojgani N, Esmaeilkhanian S, Grimes JL (2008) Screening of Indigenous Strains of Lactic Acid Bacteria for Development of a Probiotic for Poultry. Asian-Aust J Anim Sci 21, 1495-1500

Khetani TL, Nkukwana TT, Chimonyo M, Muchenje V (2009) Effect of quantitative feed restriction on broiler performance. Trop Anim Health Prod 41, 379-384

Ko SY, Bae IH, Yee ST, Lee SS, Uuganbayar D, Oh Jl, Yang CJ (2008) Comparison of the Effect of Green Tea Byproduct and Green Tea Probiotics on the Growth Performance, Meat Quality, and Immune Response of Finishing Pigs. Asian-Aust J Anim Sci 21, 1486-1494

Lee K, Shin J, Latshaw JD, Suh Y, Serr J (2009) Cloning of adipose triglyceride lipase complementary deoxyribonucleic acid in poultry and expression of adipose triglyceride lipase during development of adipose in chickens. Poult Sci 88, 620-630

Leuschner RGK, Bew J, Cruz A (2003) Enumeration of Probiotic Bacilli Spores in Animal Feed: Interlaboratory Study. J AOAC Int 86, 568-575

Liong MT, Shah NP (2005) Acid and Bile Tolerance and Cholesterol Removal Ability of Lactobacilli Strains. J Dairy Sci 88, 55-66

Lippens M, Delezie E, Maertens L, Huyghebaert G (2009) Influence of feed texture and early quantitative feed restriction on performance, growth development and carcass composition of two broiler strains. Arch Geflügelk 73, 29-40

Mountzouris KC, Tsitrsikos P, Palamidi I, Arvaniti A, Mohnl M. Schatzmayr G, Fegeros K (2010) Effect of probiotic inclusion levels in broiler nutrition on growth performance, nutrient digestibility, plasma immunoglobulins, and cecal microflora composition. Poult Sci 89, 58-67

Moritz JS, Parsons AS, Buchanan NP, Baker NJ, Jaczynski J, Gekara OJ, Bryan WB (2005) Synthetic Methionine and Feed Restriction Effects on Performance and Meat Quality of Organically Reared Broiler Chickens. J Appl Poult Res 14, 521-535

NRC (1994) Nutrient requirements of poultry. 8th ed. National Academy Press, Washington, DC, USA

Ochoa S (1955) Malic dehydrogenase from pig heart. In: Colowick SP, Kaplan NO (eds.) Methods in Enzymology, Vol. 1. Academic Press Inc., New York, USA, 735-739

Ohh SJ (2011) Meta Analysis to Draw the Appropriate Regimen of Enzyme and Probiotic Supplementation to Pigs and Chicken Diets. Asian-Aust J Anim Sci 24, 573-586

Onderci M, Sahin N, Cikim G, Aydin A, Ozercan I, Ozkose E, Ekinci S, Hayirli A, Sahin K (2008) B-Glucanaseproducing bacterial culture improves performance and nutrient utilization and alters gut morphology of broilers fed a barley-based diet. Anim Feed Sci Technol 146, 87-97

Ooi LG, Liong MT (2010) Cholesterol-Lowering Effects of Probiotics and Prebiotics: A Review of in Vivo and in Vitro Findings. Int J Mol Sci. 11, 2499-2522

Özkan S, Takma C, Yahav S, Sögüt B, Türkmut L, Erturun H, Cahaner A (2010) The effects of feed restriction and ambient temperature on growth and ascites mortality of broilers reared at high altitude. Poult Sci. $89,974-985$

Özkan S, Plavnik I, Yahav S (2006) Effects of Early Feed Restriction on Performance and Ascites Development in Broiler Chickens Subsequently Raised at Low Ambient Temperature. J Appl Poult Res 15, 9-19

Pelicano ERL, de Souza PA, de Souza HBA, Oba A, Norkus EA, Kodawara LM, de Lima TMA (2003) Effect of different probiotics on broiler carcass and meat quality. Rev Bras Cienc Avic 5, 207-214

Petek M, Sönmez G, Yildiz H, Baspinar H (2005) Effects of different management factors on broiler performance and incidence of tibial dyschondroplasia. Br Poult Sci 46, 16-21 
Pinheiro DF, Cruz VC, Sartori JR, Vicentini Paulino ML (2004) Effect of early feed restriction and enzyme supplementation on digestive enzyme activities in broilers. Poult Sci 83, 1544-1550

Plant GWE (1962) Isocitric dehydrogenase (TPN-Linked) from pig heart (revised procedure). In: Colowick SP, Kaplan NO (eds.) Methods in Enzymology, Vol 5. Academic Press, New York, USA, 645-650

Rekiel E, Wiecek J, Bielecki W, Gajewska J, Cichowicz M, Kulisiewicz J, Batorska M, Roszkowski T, Beyga K (2007) Effect of addition of feed antibiotic flavomaycin or prebiotic BIO-MOS on production results of fatteners, blood biochemical parameters, morphometric indices of intestine and composition of microflora. Arch Tierz 50 (Special Issue), 172-180

Rifai N, Warnick GR, McNamara JR, Belcher JD, Grinstead GF, Frantz ID (1992) Measurement of low-densitylipoprotein cholesterol in serum: a status report. Clin Chem 38, 150-160

Saffar A, Khajali F (2010) Application of Meal Feeding and Skip-A-Day Feeding With or Without Probiotics for Broiler Chickens Grown at High-Altitude to Prevent Ascites Mortality. Am J Anim Vet Sci 5, 13-19

Saleh EA, Watkins SE, Waldroup AL, Waldroup PW (2005) Effects of Early Quantitative Feed Restriction on Live Performance and Carcass Composition of Male Broilers Grown for Further Processing. J Appl Poult Res 14, 87-93

SAS Institute (2003) SAS User's Guide.Version 9.1 ed. SAS Institute Inc., Cary, NC, USA

Santoso U (2001) Effects of Early Feed Restriction on Growth, Fat Accumulation and Meat Composition in Unsexed Broiler Chickens. Asian-Aust J Anim Sci 14, 1585-1591

Svihus B, Sacranie A, Denstadli V, Choct M (2010) Nutrient utilization and functionality of the anterior digestive tract caused by intermittent feeding and inclusion of whole wheat in diets for broiler chickens. Poult Sci $89,2617-2625$

Sudha MR, Chauhan P, Dixit K, Babu S, Jamil K (2009) Probiotics as complementary therapy for hypercholesterolemia. Biol Med 1, Rev4

Tahmoorespur M, Ghazanfari S, Nobari K (2010) Evaluation of adiponectin gene expression in the abdominal adipose tissue of broiler chickens: Feed restriction, dietary energy, and protein influences adiponectin messenger ribonucleic acid expression. Poult Sci 89, 2092-2100

Tellez G, Higgins SE, Donoghue AM, Hargis BM (2006) Digestive Physiology and the Role of Microorganisms. J Appl Poult Res15, 136-144

Urdaneta-Rincon M, Leeson S (2002) Quantitative and qualitative feed restriction on growth characteristics of male broiler chickens. Poult Sci 81, 679-688

Vilà B, Fontgibell A, Badiola I , Esteve-Garcia E, Jiménez G, Castillo M, Brufau J (2009) Reduction of Salmonella enterica var. Enteritidis colonization and invasion by Bacillus cereus var. toyoi inclusion in poultry feeds. Poult Sci 88, 975-979

Wijtten PJA, Hangoor E, Sparla JKWM, Verstegen MWA (2010) Dietary amino acid levels and feed restriction affect small intestinal development, mortality, and weight gain of male broilers. Poult Sci 89, 1424-1439

Xiangqian LI, Qiang LI, Chuanlai XU (2008) Effect of Supplementation of Fructooligosaccharide and/or Bacillus Subtilis to Diets on Performance and on Intestinal Microflora in Broilers. Arch Tierz 51, 64-70

Xu ZR, Wang MQ, Mao HX, Zhan XA, Hu CH (2003) Effect of L-carnitine on growth performance, carcass composition, and metabolism of lipids in male broilers. Poult Sci 82, 408-413

Li L, Xu CL ,Ji C, Ma Q, Hao K, Jin ZY, Li K (2006) Effects of a dried Bacillus subtilis culture on egg quality. Poult Sci 85, 364-368

Yang X, Zhuang J, Rao K, Li X, Zhao R (2010) Effect of early feed restriction on hepatic lipid metabolism and expression of lipogenic genes in broiler chickens. Res Vet Sci 89, 438-444

Zhan XA, Wang M, Ren H, Zhao RQ, Li JX, Tan ZL (2007) Effect of Early Feed Restriction on Metabolic Programming and Compensatory Growth in Broiler Chickens. Poult Sci 86, 654-660

Zhou X, Wang Y, Gu Q, Li W (2010) Effect of dietary probiotic, Bacillus coagulans, on growth performance, chemical composition, and meat quality of Guangxi Yellow chicken. Poult Sci 89, 588-593 